\title{
KARAKTERISTIK PORI DAN HUBUNGANNYA DENGAN PERMEABILITAS PADA TANAH VERTISOL ASAL JENEPONTO SULAWESI SELATAN
}

\author{
The Characteristics of Soil Pores and The Relationship with Permeability of Vertsiol from \\ Jeneponto District of South Sulawesi \\ "Masria, ${ }^{* *}$ Christianto Lopulisa, ${ }^{* *}$ Hazairin Zubair, ${ }^{* *}$ Burhanuddin Rasyid \\ "Mahasiswa program Doktor pascasarjana Universitas Hasanuddin \\ *** Jurusan Ilmu Tanah, Fakultas Pertanian, Universitas Hasanuddin \\ (Corresponding email; masriadimyati@yahoo.co.id)
}

\begin{abstract}
This study aims to determine the characteristics of soil pores and the relationship of pore characteristics with soil permeability. Soil samples were collected from Punagaya Village, Bangkala District, Jeneponto Regency, South Sulawesi. Soil samples were taken from 20 observation points representing two types of land use ie cultivated land and fallow field at a depth of 0-60 cm. Soil analysis $(\mathrm{pH}$, organic material, C-organic, cation exchange capacity, bulk density and soil texture), Pore characteristics (porosity, pore distribution and pore stability), and permeability. Analysis of soil properties and pore characteristics was descriptive, while the relationship between pore characteristics and permeability was analyzed by single or multiple regression and correlation analysis. The results showed that the permeability of soil vertisol $0.29 \mathrm{~cm} / \mathrm{h}$ (slow) and the average value of soil pore characteristics of vertisol as follows: porosity ranged $56.49 \%$, fast drainage pore $4.35 \%$, water pore available $17.8 \%$ And $32.5 \%$ micro pores, and $36.46 \%$ pore stability. Based on the regression and correlation test, it is known that Porosity and porosity and pore stability index have the greatest influence on permeability.
\end{abstract}

Keywords: $\quad$ Pore Characteristics, Permeability, Vertisol

\section{PENDAHULUAN}

Porositas tanah didefinisikan sebagai ruang fungsional yang menghubungkan tubuh tanah dengan lingkungannya (Lal dan Shukla, 2004). Pori tanah memegang peranan penting dalam menentukan sifat fisik, kimia dan biologi tanah (Pagliai et al., 2004; Hajnos et al., 2006; Oorts et al., 2007; Smucker et al., 2007; Munkholm et al., 2012; Sleutel et al., 2012).

Sistem pori tanah sangat dipengaruhi oleh banyak faktor seperti jumlah bahan organik, jenis dan jumlah liat, kelembaban, pemadatan tanah dan manajemen tanah (Kutilek et al., 2006; Wairiu and Lal, 2006; Chun et al., 2008; Churchman et al., 2010).

Karakteristik pori menggambarkan jumlah, ukuran, distribusi, kontinuitas dan stabilitas pori tanah (Kay, 1990). Karakteristik pori tanah sangat berperan besar dalam menentukan pergerakan air dalam tanah (Hillel, 1980; Kay, 1990) dan mempengaruhi kemampuan tanah dalam meretensi air (Elrick et al., 2004). Sebagai suatu sistem, masing-masing karakter akan saling mempengaruhi satu dengan lainnya. Setiap perubahan pada satu karakter akan mempengaruhi karakter yang lain. Perubahan terhadap pori akan mengurangi jumlah, ukuran dan kuantinuitas pori (Wahyunie, 2009).

Air menempati ruang pori di dalam
tanah. Berdasarkan diameter ruangnya
Jongerius (1957) membagi pori tanah


menjadi 3 kelas, yakni : makropori dengan diameter $\geq 90 \mathrm{~mm}$, mesopori $(90-30 \mathrm{~mm})$ dan mikropori $(<30 \mu \mathrm{m})$. Air yang terikat pada mikropori merupakan air higrokopis atau tidak tersedia bagi tanaman.

Pergerakan air dalam tanah atau konduktivitas hidraulik tanah terbagi atas dua, yakni konduktivitas hidraulik jenuh (permeabilitas) dan konduktivitas hidraulik tidak jenuh. Permeabilitas tanah sangat dipengaruhi oleh karakteristik pori terutama kestabilan pori yang ditentukan oleh kestabilan agregat tanahnya. Pori yang berada dalam agregat tanah yang stabil akan mempercepat bergeraknya air, pada pori yang berada dalam agregat tanah yang tidak stabil, maka pori akan mudah tertutup akibat hancurnya agregat tanah dan menghambat pergerakan air.

Bentuk dan jumlah pori sangat dipengaruhi oleh kandungan liat tanah (Zaffar dan S.G. Lu, 2015). Tanah Vertisol merupakan tanah dengan kandungan liat yang tinggi. Kandungan liat pada vertisol lebih dari $30 \%$ di semua horison, dengan montmorillonit sebagai mineral liat yang dominan (FAO, 1990). Salah satu sifat penting dari montmorillonit adalah sifat mengembang dan mengerut yang kadarnya berhubungan dengan perubahan kandungan air tanah. Proses mengembang dan mengkerut pada tanah dengan kandungan liat tinggi secara nyata mempengaruhi perubahan pori tanah (Balbino et al., 2002; Alaoui et al., 2011).

Karakterisasi pori yang paling sering dilakukan adalah distribusi ukuran pori (Cameron and Buchan, 2006; Munkholm et al., 2012; Strong et al., 2004). Distribusi ukuran pori sangat penting dalam memahami berbagai proses dalam tanah seperti ketersediaan dan pergerakan air dalam tanah (Lipiec et al., 2006, 2012; Pagliai et al., 2004; Six et al., 2004; Strong et al., 2004). Proses mengembang dan mengerut pada tanah liat seperti Vertisol dapat menyebabkan penghancuran dan pergerakan liat yang menyebabkan tersumbatnya pori, ini merupakan fenomena yang dapat mengganggu kestabilan pori karena mengurangi ukuran dan jumlah pori. Dengan demikian selain jumlah pori, karakter pori lain yakni distribusi ukuran pori dan stabilitas pori merupakan karakter pori yang sangat penting diamati.

Oleh karena itu pemahaman tentang karakteristik pori pada tanah mengembang seperti vertisol menjadi penting dalam hubungannya dengan pergerakan air. Penelitian ini bertujuan untuk mengetahui karakteristik pori tanah (Jumlah, distribusi dan stabilitas pori) pada tanah vertisol dan Mengetahui karakteristik pori yang paling mempengaruhi pergerakan air pada tanah vertisol.

\section{METODOLOGI}

Lokasi Pengambilan contoh tanah terletak di dusun Bajipamae Desa Punagaya kecamatan Bangkala, Kabupaten Jeneponto. Sebanyak 20 contoh tanah diambil dari Vertisol yang berkembang di atas batu kapur. Lahan tempat pengambilan contoh tanah dipilih dari dua tipe penggunaan lahan yaitu lahan yang diberakan (B) dan tegalan (T) yang hanya ditanami satu kali dalam setahun. Pengambilan contoh tanah dilakukan secara utuh dengan menggunakan ring sampel, dan agregat utuh pada kedalaman $0-20 \mathrm{~cm}$

Contoh tanah utuh dipergunakan untuk analisis Bulk Density dengan metode gravimetri, permeabilitas dengan metode tinggi air konstan/konstan head method (Klute dan Dirksen, 1986), dan distribusi ukuran pori dengan menggunakan metode Pressure Plate aparatus pada $\mathrm{pF} 1, \mathrm{pF} 2, \mathrm{pF}$ 2,54 dan $\mathrm{pF} 4,2$ (Persamaan kapilaritas dan kurva pF) (Danielson and Sutherland, 1985). Jumlah pori ditetapkan berdasarkan nilai bobot isi dan bobot jenis partikel dengan menggunakan metode gravimetrik sebagai berikut: Jumlah pori ( $\%$ volume $)=(1-$ 
BI/BJP) X $100 \%$, dimana BI adalah berat isi (bulk density) dan BJP adalah berat jenis partikel tanah sebesar 2,65 (Hillel, 1986). Penetapan stabilitas pori berdasarkan pada nilai stabilitas agregat, karena pori-pori berada pada agregat tanah. Penetapan stabilitas agregat dan distribusi ukuran agregat mengikuti De Leenheer dan De Boodt (1959) dalam De Boodt, De Leenheer, dan Kirkham (1961). Selanjutnya ditetapkan indeks stabilitas agregatnya. Hasil analisis sifat-sifat tanah dan karakteristik selanjutnya dianalisis secara deskriptif untuk melihat bagaimana sifat tanah dan karakteristik pori pada tanah Vertisol, sementara hubungan karakteristik pori dengan pergerakan air dianalisis dengan menggunakan Regresi dan Korelasi baik tunggal maupun berganda.

\section{HASIL DAN PEMBAHASAN}

\section{Karakteristik Pori pada Tanah Vertisol}

\section{Porositas}

Dari hasil analisis porositas tanah diketahui bahwa porositas tanah vertisol asal Jeneponto berkisar antara 49.05 sampai $64.90 \%$ atau jika dirata-ratakan berkisar 56.49\%. Dimana nilai rata-rata porositas tanah pada lahan budidaya sebesar 57,45 \% lebih besar dibandingkan lahan yang bera sebesar 55,85 $\%$ (Tabel 1).

\section{Tabel 1. Karakteristik Pori Tanah Vertisol}

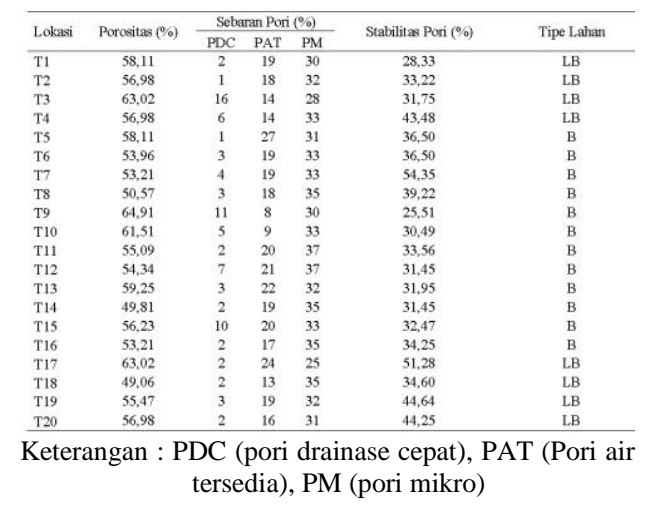

Total porositas akan mengalami peningkatan tergantung pada jumlah dan jenis material bahan organik yang ditambahkan. Sumber utama bahan organik pada lahan budidaya dilokasi penelitian berasal dari sisa brangkasan tanaman jagung yang ditanam satu kali setahun. Garza et al (2009) melaporkan bahwa penambahan bahan organik berupa residu jagung mampu meningkatkan total porositas pada tanah Vertisol.

\section{Sebaran Pori}

Sebaran pori drainase cepat pada tanah dilokasi penelitian rata-rata 4,35 atau berkisar 1-16 \% , rata-rata pori air tersedia $17,8 \%$ atau berkisar $8-24 \%$ dan rata-rata pori mikro 32,5 \% atau berkisar 28-37\%. Berdasarkan sebaran tersebut diketahui bahwa pori-pori mikro menempati ruang terbanyak di dalam pori tanah. Sistem pori tanah sangat dipengaruhi oleh bahan organik tanah, tipe dan kandungan liat, kelembaban, pemadatan dan managemen tanah (Kutilek et al., 2006; Wairiu dan Lal, 2006; Chun et al., 2008; Churchman et al., 2010). Distribusi ukuran pori merupakan kombinasi dari tekstur dan struktur tanah (Balbino et al., 2002; Bruand et al., 2004). Tanah-tanah yang didominasi fraksi pasir akan mempunyai pori makro (porous), tanah dengan dominasi debu akan banyak mempunyai pori meso (agak porous), sementara tanah dengan fraksi liat akan mempunyai banyak pori mikro (kecil) atau tidak porous (Hanafiah, 2007). Kandungan liat tanah vertisol di lokasi penelitian berkisar 59-91\%.

\section{Stabilitas Pori}

Stabilitas pori tanah berkisar 28,33-51,28\% dan tergolong dalam kelas indeks stabilitas tidak mantap sampai agak mantap. Secara umum stabilitas agregat tanah sangat ditentukan oleh jumlah bahan organik di dalam tanah. Siklus bahan organik sangat 
berperanan dalam mempengaruhi agregasi tanah melalui proses humifikasi, aktivitas mikrorganisme tanah dan eksudat yang dihasilkan oleh mikroorganisme tanah. Bravo-Garza dan Bryan (2005) melaporkan bahwa terdapat korelasi antara pengurangan agregat dan kehilangan $\mathrm{C}$ organik akibat peningkatan penggunaan lahan, tetapi tidak ada hubungan yang ditemukan untuk parameter yang sama pada lahan yang tidak terganggu.

Hal ini menunjukkan bahwa karakteristik khas dari smektit pada peran bahan organik dalam pembentukan agregat. Proses mengembang dan mengerut pada smektit dapat mempengaruhi proses mineralisasi bahan organik dan perkembangan mikrobial (Six et al., 2000). Smektit meningkatkan perlindungan terhadap bahan organik karena adanya ikatan kompleks antara bahan organik dan liat (Ranson et al., 1998 dalam Bravo-Garza et al., 2009 ) dan jebakan bahan organik dan mikroba dalam agregat (Golchin et al., 1994). Perubahan pori akibat proses mengembang dan mengerut mempengaruhi aktivitas mikroba yang akhirnya mempengaruhi tingkat dan hasil mineralisasi (Baldock, 2002 dalam Bravo-Garza et al., 2009). Pemberian bahan organik meningkatkan pembentukan makroagregat (>200 mm), akan tetapi proses mengembang dan mengerut mempengaruhi pembentukan dan stabilisasi makroagregat (Bravo-Garza et al., 2009).

\section{Hubungan Karakteristik Pori dengan Pergerakan Air pada Tanah Vertisol}

Rata-rata nilai permeabilitas tanah (konduktivitas hidraulik jenuh) sebesar 0,29 $\mathrm{cm} / \mathrm{jam}$ atau tergolong lambat, dengan koefisien variasi 67,68\%. Dengan nilai koefisien variasi sebesar 67,68\% tergolong normal, sebab permeabilitas tanah dan karakteristik pergerakan gas dan air dapat mempunyai koefisen keragaman > $100 \%$ (Jury et al., 1989; Wilding, 1985).

Tabel 2. Nilai rata-rata Permeabilitas Tanah

\begin{tabular}{cc}
\hline Parameter & Nilai \\
\hline Permeabilitas & 0,2975 \\
sd & 0,20165 \\
CV & $67,68 \%$ \\
N & 20 \\
\hline Untuk melihat hubungan antara
\end{tabular}

karakteristik pori dengan permeabilitas tanah dilakukan analisis regresi dan korelasi baik secara tunggal dan ganda, yang disajikan pada Tabel 3.

Berdasarkan analisis regresi dan korelasi tunggal diketahui bahwa ruang pori total mempunyai hubungan yang lebih besar dibandingkan indeks stabilitas pori, Pori drainase cepat dan pori air tersedia. Tabel 3 menunjukkan bahwa permeabilitas tanah meningkat dengan makin besarnya ruang pori total dan stabilitas agregat dengan koefisen korelasi sebesar 0,61. Begitu juga dengan pori drainase cepat dan pori air tersedia yang semakin meningkatkan pergerakan air dengan meningkatnya stabilitas agregat.

Ruang pori drainase cepat merupakan ruang pori dengan selang ukuran diameter pori lebih besar daripada ruang pori drainase maupun ruang pori tersedia. Seperti telah disebutkan oleh Korevaar et al. (1983), ruang pori yang paling berpengaruh terhadap permeabilitas adalah ruang pori terbesar yang masih terisi air, sehingga ruang pori drainase cepat bersama stabilitas agregat berkorelasi/berpengaruh paling besar terhadap permeabilitas. Semakin banyak proporsi ruang pori dengan selang ukuran lebih besar dan makin stabil pori di dalam agregat tanah, maka lebih banyak ruang pori yang dapat menghantarkan air sehingga permeabilitas makin besar. 
Tabel 3. Regresi antara Karakteristik Pori dengan Pergerakan Air Tanah

\begin{tabular}{|c|c|c|c|}
\hline No & Peubah & Persamaan Regresi & Korel: \\
\hline 1. & RPT & $\mathrm{Y}=-1,088+0,25 \mathrm{x}$ & 0,53 \\
\hline 2. & ISA & $Y=0,094+0,06 X$ & 0,20 ? \\
\hline 3. & PDC & $\mathrm{Y}=0,218+0,18 \mathrm{x}$ & 0,35 \\
\hline 4. & PAT & $\mathrm{Y}=0,319-0,01 \mathrm{X}$ &,$- 02^{\prime}$ \\
\hline 5. & RPT,ISA & $\mathrm{Y}=-1,478+0,26 \mathrm{RPT}+0,08 \mathrm{ISA}$ & 0,61 \\
\hline 6. & PDC, ISA & $\mathrm{Y}=-1,40+0,23 \mathrm{PMk}+0,09 \mathrm{ISA}$ & 0,37 \\
\hline 7. & PAT, ISA & $\mathrm{Y}=0,143-0,005 \mathrm{PMs}+0,06 \mathrm{ISA}$ & 0,41 \\
\hline
\end{tabular}

Lebih rendahnya pengaruh ruang pori air tersedia dibanding ruang pori drainase cepat

bersama stabilitas pori dalam agregat; karena ruang pori air tersedia terdiri dari ruang pori makro dan sebagian ruang pori mikro yang dapat mengikat air secara kuat sehingga dapat menghambat pergerakan air. Air dalam ruang pori kapiler (ruang pori air tersedia) dapat bergerak apabila ada tekanan (potensial) hidrolik yang tinggi. Keadaan ini dapat tercapai bila lapisan tanah di atas ruang pori air tersedia tersebut mencapai jenuh dengan ketebalan tertentu.

\section{KESIMPULAN}

1. Nilai rata-rata karakteristik pori tanah vertisol sebagai berikut porositas berkisar $56,49 \%$, pori drainase cepat sebesar 4,35 $\%$, pori air tersedia $17,8 \%$ dan pori mikro $32,5 \%$, dan stabilitas pori sebesar 36,46 $\%$.

2. Berdasarkan uji regresi dan korelasi diketahui bahwa karakter Porositas dan kombinasi porositas dan indeks stabilitas pori mempunyai pengaruh terbesar terhadap permeabilitas tanah.

\section{DAFTAR PUSTAKA}

Alaoui, A., Lipiec, J. and Gerke, H. H. 2011. A review of the changes in the soil pore system due to soil deformation: A hydrodynamic perspective. Soil Till. Res. 115-116: 1-15.

Balbino, L. C., Bruand, A., Brossard, M., Grimaldi, M., Hajnos, M. and Guimar aes, M. F. 2002. Changes in porosity and microaggregation in clayey Ferralsols of the Brailian Cerrado on clearing for pasture. Eur. J. Soil Sci. 53: 219-230.

Bravo-Garza, M.R., Bryan, R.B., 2005. Soil properties along cultivation and fallow time sequences on Vertisols in Northeastern Mexico. Soil Science Society of America Journal 69, 473481.

Cameron, K. C. and Buchan, G. D. 2006. Porosity and pore size distribution. In Lal, R. (ed.) Encyclopedia of Soil Science. CRC Press, Boca Raton. pp. 1350-1353.

Chun, H. C., Gimđenez, D. and Yoon, S. W. 2008. Morphology, lacunarity and entropy of intra-aggregate pores: Aggregate size and soil management effects. Geoderma. 146: 83-93.

Dixon J.B, 1991. Roles of Clays in Soils. Applied Clay Science, (5); 489-503.

De Boodt, M., De Leenheer, L., dan Kirkham, D. 1961. Soil aggregate stability indexes and crop yield. Soil Sci. 91:138-146.

Hanafiah, K, A., 2007. Dasar-dasar Ilmu Tanah. Rajawali Pers. Jakarta.

Hillel, D., 1980. Fundamentals of Soil Physics. Academic Press. New York.

Hajnos, M., Lipiec, J., IISwieboda, R., SokoÃlowska, Z. and Witkowska- 
Walczak, B. 2006. Complete characterization of pore size distribution of tilled and orchard loamy soil using water retention curve, mercury porosimetry, nitrogen adsorption, and water desorption methods. Geoderma. 135: 307-314.

Jury, W.A., Sposito, G. And R.E. White. 1989. A Transfer Function Model of Solute Transport Through Soil. I. Fundamental Conceps. Water Resources Research. 22 : 243-247.

Kay, D. 1990. Rates of changes of soil structure under different cropping systems. Adv. Soil Sci. 12:1-52.

Kutilek, M., Jendele, L. and Panayiotopoulos, K. P. 2006. The influence of uniaxial compression upon pore size distribution in bi-modal soils. Soil Till. Res. 86: 27-37.

Lal, R. dan M. K. Shukla. 2004. Principles of Soil Physics. Marcel Dekker, Inc.New York

Klute, A. dan C. Dirksen. 1986. Hydraulic conductivity and diffusivity: laboratory methods. In A. Klute (eds) Methods of Soil Analysis. Am. Soc.Agron. Inc, Soil Sci. Soc. Am. Inc Madison, Wisconsin USA.

Lipiec, J., Hajnos, M. and Swieboda, R. 2012. Estimating effectsof compaction on pore size distribution of soil aggregates by mercury porosimeter. Geoderma. 179-180: 20-27.

Munkholm, L. J., Heck, R. J. and Deen, B. 2012. Soil pore characteristics assessed from X-ray micro-CT derived images and correlations to soil friability. Geoderma. 181-182: 22-29.
Munkholm, L. J., Heck, R. J. and Deen, B. 2012. Soil pore characteristics assessed from X-ray micro-CT derived images and correlations to soil friability. Geoderma. 181-182: 22-29

Oorts, K., Bossuyt, H., Labreuche, J., Merckx, R. and Nicolardot, B. 2007. Carbon and nitrogen stocks in relation to organic matter fractions, aggregation and pore size distribution in no-tillage and conventional tillage in northern France. Eur. J. Soil Sci. 58: 248-259.

Pagliai, M., Vignozzi, N. and Pellegrini, S. 2004. Soil structure and the e ${ }^{\circledR e c t}$ of management practices. Soil Till. Res. 79: 131-143.

Six, J., E.T. Elliott, dan K. Paustian. 1999. Aggregate and soil organic matter dynamics under conventional and notillage system. Soil Sci. Soc. Am.J. 63:1350-1358.

Sleutel, S., Bouckaert, L., Buchan, D., Van Loo, D., Cornelis, W.M. and Sanga, H. G. 2012. Manipulation of the soil pore and microbial community structure in soil mesocosm incubation studies. Soil Biol. Biochem. 45: 40-48.

Smucker, A. J. M., Park, E. J., Dorner, J. and Horn, R. 2007. Soil micropore development and contributions to soluble carbon transport within macroaggregates. Vadose Zone $J$. 6:282-290.

Schjonning, P., Christensen, B.T., Carstensen, B., 1994. Physical and chemical properties of a sandy loam receiving animal manure, mineral fertilizer or no fertilizer for 90 years. Eur. J. Soil Sci. 45, 257-268. 
Wahjunie, E.D., Haridjaja, O., Soedodo, H., Sudarsono. 2006. Pergerakan Air Tanah pada Pori Berbeda dan Pengaruhnya pada Ketersediaan Air bagi Tanaman. Jurnal Tanah dan Iklim (28) : 15-26.

Wairiu, M. and Lal, R. 2006. Tillage and land use effects on soil microporosity in Ohio, USA and Kolombangara, Solomon Islands. Soil Till. Res. 88: 8084.

Wanjari, R.H., Ravankar, H.N., Mishra, B., Saha, M.N., Singh, Y.V., Sahi, D.K., Sarap, P.A., 2005. Long-term effect of fertilizer and manure application on soil organic carbon storage, soil quality and yield sustainability under subhumid and semi-arid tropical India. Field Crops Res. 93, 264-280.

Wilding, L.P. 1985. Spatial Variability : Its Documentation, Accomodation, and Implication to Soil Surveys. P. 166189. In Nielsen, D.R., and J. Bouma (eds). Soil Spatial Variability. Proceeding of the Workshop ISSS and SSSA, Las Vegas, N.V. 30 November1 December 1984. PUDOC, Wageningen. The Netherlands.

Tiarks, A.E., Mazurak, A.P., Chesnin, L., 1974. Physical and chemical properties of soil associated with heavy applications of manure from cattle feedlots. Soil Sci. Soc. Am. Proc. 38, 826-830.

Zaffar, M., Gao, L.S. 2015. . Pore Size Distribution of Clayey Soils and Its Correlation with Soil Organic Matter. Pedhospere (25) 240-249. 